\title{
Functional Disability and Health-Related Quality Of Life in South Africans with Early Rheumatoid Arthritis
}

\author{
B Hodkinson $^{1}$, E Musenge ${ }^{2}$, M Ally $^{3}$, PWA Meyer ${ }^{4}$, R Anderson $^{4}, \mathrm{M} \mathrm{Tikly}^{1}$ \\ ${ }^{1}$ Division of Rheumatology, Department of Medicine, Chris Hani Baragwanath Hospital, University of the \\ Witwatersrand, Johannesburg, South Africa \\ ${ }^{2}$ Biostatistics and Epidemiology Division, School of Public Health, Faculty of Health Sciences, University of the \\ Witwatersrand, Johannesburg, South Africa \\ ${ }^{3}$ Department Internal Medicine, University of Pretoria, Pretoria, South Africa \\ ${ }^{4}$ Medical Research Council Unit for Inflammation and Immunity, Department of Immunology, Faculty of Health \\ Sciences, University of Pretoria and NHLS, Tshwane Academic Division, Pretoria, South Africa \\ Bridget Hodkinson, Division of Rheumatology, Department of Medicine, Chris Hani Baragwanath Hospital, \\ PO Box Bertsham 2013, South Africa. E-mail: drbridget@gmail.com
}

\begin{abstract}
Background: The severity and predictors of functional disability and health-related quality of life (HRQoL) in a cohort of South Africans with early RA were investigated. Methods: Changes in the Health Assessment Questionnaire-disability index (HAQ) and the Short Form-36 (SF-36) following 12 months of traditional disease modifying anti-rheumatic drugs (DMARDs) were studied in previously DMARD-naïve adults with disease duration $\leq 2$ years. Results: The majority of the 171 patients were female (82\%), black Africans $(89 \%)$ with a mean (SD) symptom duration of $11.6(7.0)$ months. In the 134 patients seen at 12 months, there were significant improvements in the HAQ and all domains of the SF-36, but $92(69 \%)$ still had substantial functional disability (HAQ >0.5), and $89(66 \%)$ had suboptimal mental health (SF-36 mental composite score $<66.6)$. Multivariate analysis showed that female sex $(p=0.05)$ and high baseline HAQ $(\mathrm{p}<0.01)$ predicted substantial functional disability at 12 months. Unemployment
\end{abstract}


$(\mathrm{p}=0.03)$, high baseline pain $(\mathrm{p}=0.02)$ and HAQ $(\mathrm{p}=0.04)$ predicted suboptimal mental health, with a trend towards low level of schooling being significant $(\mathrm{p}=0.08)$. Conclusions: Early RA has a broad impact on HRQoL in indigent South Africans, with a large proportion of patients still showing substantial functional disability and suboptimal mental health despite 12 months of DMARD therapy. Further research is needed to establish the role of interventions including psycho-social support, rehabilitation programmes and biologic therapy to improve physical function and HRQoL in this population.

Keywords functional disability, health-related quality of life, South Africa, socio-economic status

Joint inflammation and consequent damage can potentially cause serious disability in rheumatoid arthritis (RA). Modern RA therapy is aimed at restoring activities of daily life, psychological health, and preservation of social and occupational roles through early aggressive control of disease activity. Traditional clinical and laboratory measures of disease activity and severity do not adequately capture aspects of physical disability and psychosocial aspects of the disease(1).

The modified Health Assessment Questionnaire-disability index (HAQ), a disease specific measure of physical disability, and the Medical Outcomes Short Form-36 (SF-36), a generic health-related quality of life (HRQoL) instrument, are widely used self-administered questionnaires in $\operatorname{RA}(2,3)$. These measures show good correlation with markers of disease activity(4), especially in early disease; are responsive to treatment(5); are good indicators of the indirect costs of RA(6); and are predictive of long term disability and mortality(7). Moreover, 
instruments that measure HRQoL in RA incorporate the patient's perspective of health status, an aspect that is often overlooked in routine clinical practice(1).

In established RA, physical function worsens progressively with time, mainly as a consequence of irreversible joint damage(8) and HRQoL is significantly impaired across all domains $(9,10)$. By contrast, in early RA, physical disability, as measured by the HAQ, is driven principally by disease activity, specifically synovitis and pain, and improves with effective treatment(11). General HRQoL, as measured by the SF-36, similarly shows a heavy burden of physical disability and pain with impaired social function, low vitality scores, and poor mental health in early RA(12-14) .

Socio-demographic and psychosocial factors impact on the overall burden of RA. Low levels of formal education and poor socio-economic status (SES) are risk factors for poorer outcome in RA in industrialized countries(15-17). Cross-sectional studies of South Africans with established RA have shown poor HRQoL, impaired functional ability and high rates of depression(18-20). Amongst indigent South Africans, access to rheumatology care is limited. Recognition and referral of early inflammatory arthritis is often delayed at primary care level, and there are few state-sector specialist rheumatology clinics with no access to biologic therapy.

In the absence of any published longitudinal studies of disability and HRQoL in RA in sub-Saharan Africa, we undertook a prospective observational study in South Africans with early RA to evaluate functional disability and HRQoL over 12 months and to identify predictors of poor physical and mental health.

\section{Patients and Methods}

A cohort of 171 consenting patients with disease modifying anti-rheumatic drug 
(DMARD)-naïve early RA, defined as disease duration $\leq 2$ years, were enrolled between 2005 and 2008 as part of the Gauteng Region Early Arthritis (GREAT) registry. The registry is a multifaceted ongoing project at 2 tertiary state-sector hospitals in Gauteng, South Africa, which serve a mainly indigent urban and peri-urban population. All patients met the modified 1987 American College of Rheumatology classification criteria for RA(21). Demographic variables collected included age, gender, symptom duration, current employment and the number of school years completed.

The HAQ, SF-36, simplified disease activity Index (SDAI)(22) and a pain, patient global assessment and physician global score were completed at baseline and at 12 months. The minimally clinically important difference (MCID), defined as the smallest improvement in a score that patients perceive as beneficial, of -0.25 and 5 for the HAQ and SF-36 scores respectively, was used(23, 24). Predictors of functional disability were analyzed by comparing patients with "minimal" functional disability, defined as a HAQ $\leq 0.5$, to those with "substantial" functional disability, defined as HAQ $>0.5$, at 12 months. The SF-36 mental composite score (MCS) was used as a measure of overall mental health, and an arbitrary cutoff score of 66.6 was used to define patients with "good" mental health $(\geq 66.6)$ and "suboptimal" mental health $(<66.6)$.

\section{Treatment}

Patients were reviewed at 2-4 monthly intervals at routine follow-up visits and treated with DMARDs with or without low-dose prednisone $(\leq 7.5 \mathrm{mg} /$ day $)$. Changes in DMARD therapy were made at the discretion of the attending physician according to efficacy and tolerance. Poor adherence to therapy was defined as patient's self-reported failure to take DMARDs as prescribed for one month or longer. 


\section{Statistical analysis}

The Students $t$ test was applied to compare continuous variables between groups, except where the data showed a non-normal distribution, in which case the Wilcoxon rank sum test was used. The Chi-square test, or where indicated, the 2-tailed Fishers' exact test was used for categorical variables. Spearman correlation coefficients were applied to assess correlations between continuous variables. Multivariate analysis was performed using stepwise backward logistic regression, and demographic and baseline variables with a $p$-value $\leq 0.15$ in the univariate analysis were included in the model. A p-value of 0.05 was considered significant. All statistical analyses were done using Stata 10 software (StataCorp, USA).

The study was approved by the University of the Witwatersrand Committee for Research on Human Subjects.

Results

Baseline characteristics

Most patients were female (82\%), Black Africans (89\%) with a mean (SD) age of 47.0 (12.5) years and symptom duration of 11.6 (7.0) months. Rheumatoid factor and anti-cyclic citrullinated antibodies were positive in $85 \%$ and $81 \%$ respectively. Patients had severe disease with a mean (SD) SDAI of 39.4 (16.2), HAQ of 1.7 (0.8), and scored low in all domains of the SF-36 with physical composite score (PCS) and MCS scores of 34.2 (16.9) and 44.9 (18.5). The majority were of a poor socio-economic background: the mean number of school years completed was 9 (range $0-12$ years); no patient had college or university education and 55\% were unemployed.

Therapy and outcome at 12 months 
Two patients died of respiratory infections, both in the first 6 months, and 35 (20\%) were lost to follow-up. In the remaining 134 patients who completed the 12 -month visit, most (91\%) were treated with methotrexate as monotherapy or in combination with chloroquine (CQ) and/or sulphasalazine (SSZ), and the remaining patients received SSZ (6\%) or CQ monotherapy (3\%). The starting dose of MTX was between 7.5 and 15mg/week (mean (SD) dose 13.1 (3.2) $\mathrm{mg} /$ week), and by month 12 the maximum dose was $25 \mathrm{mg} /$ week (mean (SD) dose 20.0 (4.3) $\mathrm{mg} /$ week). Low dose prednisone (5-7.5mg/day) was prescribed in $90(52 \%)$ patients. There were no cases where the dose of DMARD or prednisone was limited by liver toxicity or septicaemia. Poor adherence to therapy was observed in almost a quarter of patients. Improvements in HAQ and SF-36 at 12 months

At 12 months, HAQ and SF-36 scores improved significantly, and the percentage of patients achieving a MCID for the HAQ, SF- 36 PCS and MCS was 64, 58 and 43 respectively (Table 1). There was improvement across all individual domains of the SF-36 (Figure 1), with the most impressive improvements in the area of bodily pain and role emotional. Patients performed worst in the role-physical domain, both at baseline and at 12 months. Despite these improvements, only 42 patients (31\%) achieved minimal functional disability and 45 (34\%) good mental health at 12 months. To allow less abstract interpretation of the SF-36 results, responses to selected questions at baseline and at 12 months are shown in Figure 2. A large proportion of patients continued to experience difficulties in all categories, and in particular showed limitations in lower limb activities (33\% of patients were unable to climb a flight of stairs), social activities ( $25 \%$ felt activities were limited by health), and high levels of pain causing interference with daily life (36\% had pain intruding on activities of daily living).

\section{Correlations}


At 12 months the HAQ correlated significantly with disease activity, pain, patient and physician global assessments (Table 2), with very strong correlations between the HAQ and the mental subscales of the SF-36. The pain score correlated with the HAQ, and with all SF-36 domains except mental health.

\section{Predictors of 12-month functional disability}

Analysis of predictors of response was restricted to the 134 patients who completed the 12 month follow-up visit. Univariate analysis, comparing the minimal functional disability and the substantial functional disability groups, showed that gender, the baseline HAQ and pain scores were significantly different between the groups, with a trend towards a difference in the number of school years, employment rate and adherence to DMARD therapy (Table 3). At 12 months, patients with minimal functional disability had significantly lower pain and SDAI scores, and had achieved a greater improvement in both pain and disease activity than patients with substantial physical disability.Neither the type nor dose of DMARD therapy, nor whether or not low dose corticosteroids were prescribed predicted the 12 month status.

Multivariate analysis showed that female gender and a high baseline HAQ were independent baseline predictors of substantial functional disability. Predictors of 12-month mental health status

Univariate analysis, comparing patients who achieved good mental health to those with suboptimal mental health revealed that level of formal education, employment, baseline pain, patient global and HAQ scores were significant (Table 4). Females fared worse; as did those who were poorly adherent to treatment but these differences did not reach statistical significance, most likely because of the relatively small size of the study. The 12-month pain score, SDAI and HAQ were significantly higher in the patients with suboptimal mental health, and these patients 
had less improvement in each of these areas. In the multivariate model, unemployment, high baseline HAQ and pain scores were independently associated with suboptimal mental health. Patients lost to folliow-up

No significant differences in demographics, SDAI, HAQ or SF 36 scores at baseline were observed between the patients who were lost to follow-up versus those who completed the study.

Discussion

To the best of our knowledge, this is the first study to examine longitudinal changes in functional disability and HRQoL in sub-Saharan Africans with RA. It confirms the tremendous burden of early RA on a background of socio-economic depravity. Despite significant improvements in the group overall, more than a third of patients failed to achieve clinically meaningful improvement in physical disability after 12 months of treatment with traditional DMARD therapy and "routine" clinic care. A third of patients continued to struggle to climb a flight of stairs and could not shop for groceries independently, underscoring the difficulties experienced by our patients in performing activities of daily living. A previous cross sectional study of South Africans with established RA shows construct validity of the HAQ and the SF-36 questionnaires in this population, and reports significant physical disability(18). Elsewhere in the developing world a recent study in Thailand showed significant functional deterioration over 1 year of DMARD therapy(25).

The central role of pain in our RA patients' symtomatology and its negative impact on physical and social activities is demonstrated by the strong correlations between the pain scores and the HAQ, vitality and social functioning. In a qualitative study Schneider et al found pain to 
be a key experience of women with RA in Soweto, South Africa where low income and the lack of services compound social exclusion and loss of independence(26).

Moreover, this study demonstrates the high number of patients with poor mental health, where two thirds of patients had "suboptimal mental health" at their 12-month visit. We observed strong correlations between the mental subscales of the SF-36 including role emotional, vitality and social functioning with the HAQ. These relationships are likely to be bidirectional, as poor functional disability could contribute to suboptimal mental health, but equally, low mood and vitality levels could worsen physical function and perceptions of disability.

Predictors of functional disability and mental health were similar, and included baseline disability, pain and mental health, but not disease activity. These findings are consistent with previous studies, where a poor HAQ score early in the disease is an important predictor of future disability(27-31), and pain and depression are major contributors to both physical disability and HRQoL(30, 32-36). Poor improvement in pain, disease activity and HAQ scores, and as a result had higher 12-month scores, were associated with worse physical function and mental health scores.

Most patients in this study were of a low SES background, and worse physical and mental health scores were seen amongst unemployed patients and those with less formal education. Previous studies in industrialized countries have shown that fewer years of schooling and poor SES impact negatively on disease activity, mental and emotional health and overall mortality rates $(17,37,38)$. The QUEST-RA studies in 25 countries showed an association between gross domestic product and disease status, including physical disability and psychological health(39). Margaretten et al refer to a "vulnerable population" of RA patients 
where background poverty and high functional disability give rise to a high risk for mental illhealth(40).

Several factors may explain the profound impact of SES on disease expression. Delays in initiating DMARDs may be a reason for poorer outcome amongst indigent patients(41), and in keeping with this our patients presented relatively late after symptom onset. This is a result of a low awareness of symptoms and available treatments, and limited access to health care. Callahan et al suggest certain lifestyle factors associated with poverty lead to worse health outcomes, some of which may be applicable to our study population - poor diet, less exercise, and low social support(37). Underutilization of available resources, in particular allied health care, amongst less educated patients has been described in the Netherlands(42). These aspects were not investigated in the present study, but they may be important factors in our patients. In addition, education may confer better coping skills - and this may mediate illness perception and the overall impact of a chronic illness such as RA(43).

That females emerged with worse HAQ scores at 12 months is consistent other studies $(44,45)$. One explanation is a difference in perception of functional disability, where males underestimate their disability(46). Almost a quarter of patients admitted poor adherence to their DMARD medication, and these patients fared worse. This has been shown by others(47). Whilst previous studies have shown that older age at disease onset is associated with higher physical disability scores $(28,48)$, this was not evident in our study, perhaps due to the small proportion of elderly patients in our cohort.

One of the limitations of this study was the high number of patients lost to follow-up, which is probably a reflection of poor SES where financial difficulties and poor public transport 
facilities make it difficult for patients to keep their follow-up appointments. Another shortcoming is that we did not use a questionnaire to specifically measure depression and relied on the SF-36 MCS to measure mental health. Thirdly, patients included in this study reflect a referral bias where only the more severe patients are referred to tertiary hospitals, and hence results of this study are not generalisable to all South African populations.

This study shows the need for further studies assessing the place of interventions aimed at improving health status of RA patients in this population. These might include physical and occupational therapies and psychosocial support programmes combined with pharmacological treatment of depression and more aggressive therapy of disease per se with biologic drugs. There is evidence for such strategies: antidepressants in depressed patients with musculoskeletal disease have been shown to improve not only mental health status, but physical disability and pain scores(49), and biologic drug therapy in early RA patients reduces depression and improves outcomes in patients who achieve remission(50).

In summary, this study demonstrates the broad negative impact of early RA on functional disability and HRQoL in impoverished South African patients. Further studies are required to assess the role of more active rehabilitation and psychosocial support together with hitherto prohibitively costly biologic drugs in this population.

\section{Conflict of interest statement}

The authors declare no conflicts of interest.

Acknowledgements

This work was supported by the Connective Tissue Diseases Research Fund, University of the 
Witwatersrand and the Medical Research Council of South Africa.

The authors thank Mrs Nthabiseng Monyai for data collection

\section{References}

1. Lubeck DP. Health-related quality of life measurements and studies in rheumatoid arthritis. Am J Manag Care 2002;8:811-20.

2. Kirwan JR, Reeback JS. Stanford Health Assessment Questionnaire modified to assess disability in British patients with rheumatoid arthritis. Br J Rheumatol 1986;25:206-9.

3. Ware JE, Jr., Sherbourne CD. The MOS 36-item short-form health survey (SF-36). I. Conceptual framework and item selection. Med Care 1992;30:473-83.

4. Wolfe F. The determination and measurement of functional disability in rheumatoid arthritis. Arthritis Res 2002;4 Suppl 2:S11-5.

5. Tugwell P, Wells G, Strand V, Maetzel A, Bombardier C, Crawford B, et al. Clinical improvement as reflected in measures of function and health-related quality of life following treatment with leflunomide compared with methotrexate in patients with rheumatoid arthritis: sensitivity and relative efficiency to detect a treatment effect in a twelve-month, placebo-controlled trial. Leflunomide Rheumatoid Arthritis Investigators Group. Arthritis Rheum 2000;43:506-14.

6. Gabriel SE, Crowson CS, Campion ME, O'Fallon WM. Indirect and nonmedical costs among people with rheumatoid arthritis and osteoarthritis compared with nonarthritic controls. J Rheumatol 1997;24:43-8.

7. Pincus T. Patient questionnaires and formal education as more significant prognostic markers than radiographs or laboratory tests for rheumatoid arthritis mortality--limitations of a biomedical model to predict long-term outcomes. Bull NYU Hosp Jt Dis 2007;65 Suppl 1:S29-36.

8. Scott DL, Smith C, Kingsley G. Joint damage and disability in rheumatoid arthritis: an updated systematic review. Clin Exp Rheumatol 2003;21:S20-7.

9. Salaffi F, Carotti M, Gasparini S, Intorcia M, Grassi W. The health-related quality of life in rheumatoid arthritis, ankylosing spondylitis, and psoriatic arthritis: a comparison with a selected sample of healthy people. Health Qual Life Outcomes 2009;7:25.

10. Soderlin MK, Lindroth Y, Jacobsson LT. Trends in medication and health-related quality of life in a population-based rheumatoid arthritis register in Malmo, Sweden. Rheumatology (Oxford) 2007;46:1355-8.

11. Hazes JM. Determinants of physical function in rheumatoid arthritis: association with the disease process. Rheumatology (Oxford) 2003;42 Suppl 2:ii17-21.

12. Kosinski M, Kujawski SC, Martin R, Wanke LA, Buatti MC, Ware JE, Jr., et al. Health-related quality of life in early rheumatoid arthritis: impact of disease and treatment response. Am J Manag Care 2002;8:231-40.

13. Smedstad LM, Moum T, Vaglum P, Kvien TK. The impact of early rheumatoid arthritis on psychological distress. A comparison between 238 patients with RA and 116 matched controls. Scand J Rheumatol 1996;25:377-82.

14. da Mota LM, Laurindo IM, dos Santos Neto LL. Prospective evaluation of the quality of life in a cohort of patients with early rheumatoid arthritis. Rev Bras Reumatol;50:249-61.

15. Harrison MJ, Tricker KJ, Davies L, Hassell A, Dawes P, Scott DL, et al. The relationship between social deprivation, disease outcome measures, and response to treatment in patients with stable, longstanding rheumatoid arthritis. J Rheumatol 2005;32:2330-6. 
16. Vliet Vlieland TP, Buitenhuis NA, van Zeben D, Vandenbroucke JP, Breedveld FC, Hazes JM. Sociodemographic factors and the outcome of rheumatoid arthritis in young women. Ann Rheum Dis 1994;53:803-6.

17. Pincus T, Keysor J, Sokka T, Krishnan E, Callahan LF. Patient questionnaires and formal education level as prospective predictors of mortality over 10 years in $97 \%$ of 1416 patients with rheumatoid arthritis from 15 United States private practices. J Rheumatol 2004;31:229-34.

18. Benitha R, Tikly M. Functional disability and health-related quality of life in South Africans with rheumatoid arthritis and systemic lupus erythematosus. Clin Rheumatol 2007;26:24-9.

19. Mody GM, Meyers OL. Rheumatoid arthritis in blacks in South Africa. Ann Rheum Dis 1989;48:69-72.

20. Solomon A, Christian BF, Woodiwiss AJ, Norton GR, Dessein PH. Burden of depressive symptoms in South African public healthcare patients with established rheumatoid arthritis: a case-control study. Clin Exp Rheumatol.2011;29:506-12

21. Arnett FC, Edworthy SM, Bloch DA, McShane DJ, Fries JF, Cooper NS, et al. The American Rheumatism Association 1987 revised criteria for the classification of rheumatoid arthritis. Arthritis Rheum 1988;31:315-24.

22. Aletaha D, Smolen J. The Simplified Disease Activity Index (SDAI) and the Clinical Disease Activity Index (CDAI): a review of their usefulness and validity in rheumatoid arthritis. Clin Exp Rheumatol 2005;23:S100-8.

23. Kosinski M, Zhao SZ, Dedhiya S, Osterhaus JT, Ware JE, Jr. Determining minimally important changes in generic and disease-specific health-related quality of life questionnaires in clinical trials of rheumatoid arthritis. Arthritis Rheum 2000;43:1478-87.

24. Redelmeier DA, Lorig K. Assessing the clinical importance of symptomatic improvements. An illustration in rheumatology. Arch Intern Med 1993;153:1337-42.

25. Osiri M, Deesomchok U, Tugwell P. Disease activity and functional changes of RA patients receiving different DMARDs in clinical practice. Clin Rheumatol 2006;25:721-7.

26. Schneider M, Manabile E, Tikly M. Social aspects of living with rheumatoid arthritis: a qualitative descriptive study in Soweto, South Africa - a low resource context. Health Qual Life Outcomes 2008;6:54.

27. Wolfe F. A reappraisal of HAQ disability in rheumatoid arthritis. Arthritis Rheum 2000;43:2751-

61.

28. Verstappen SM, Jacobs JW, Huisman AM, van Rijthoven AW, Sokka T, Bijlsma JW. Functional Health Assessment Questionnaire (HAQ) and Psychological HAQ Are Associated with and Predicted by Different Factors in Rheumatoid Arthritis. J Rheumatol 2007;34:1837-40.

29. Combe B, Cantagrel A, Goupille P, Bozonnat MC, Sibilia J, Eliaou JF, et al. Predictive factors of 5year health assessment questionnaire disability in early rheumatoid arthritis. J Rheumatol 2003;30:23449.

30. Rupp I, Boshuizen HC, Dinant HJ, Jacobi CE, van den Bos GA. Disability and health-related quality of life among patients with rheumatoid arthritis: association with radiographic joint damage, disease activity, pain, and depressive symptoms. Scand J Rheumatol 2006;35:175-81.

31. Leigh JP, Fries JF. Predictors of disability in a longitudinal sample of patients with rheumatoid arthritis. Ann Rheum Dis 1992;51:581-7.

32. Toussirot E. Predictive factors for disability as evaluated by the health assessment questionnaire in rheumatoid arthritis: a literature review. Inflamm Allergy Drug Targets 2010;9:51-9.

33. Wolfe F, Hawley DJ. The relationship between clinical activity and depression in rheumatoid arthritis. J Rheumatol 1993;20:2032-7.

34. Affleck $G$, Urrows $S$, Tennen $H$, Higgins P. Daily coping with pain from rheumatoid arthritis: patterns and correlates. Pain 1992;51:221-9. 
35. Covic T, Adamson B, Spencer D, Howe G. A biopsychosocial model of pain and depression in rheumatoid arthritis: a 12-month longitudinal study. Rheumatology (Oxford) 2003;42:1287-94.

36. Wolfe F, Michaud K. Predicting depression in rheumatoid arthritis: the signal importance of pain extent and fatigue, and comorbidity. Arthritis Rheum 2009;61:667-73.

37. Callahan LF, Pincus T. Formal education level as a significant marker of clinical status in rheumatoid arthritis. Arthritis Rheum 1988;31:1346-57.

38. Criswell LA, Katz PP. Relationship of education level to treatment received for rheumatoid arthritis. J Rheumatol 1994;21:2026-33.

39. Sokka T, Kautiainen H, Pincus T, Toloza S, da Rocha Castelar Pinheiro G, Lazovskis J, et al. Disparities in rheumatoid arthritis disease activity according to gross domestic product in 25 countries in the QUEST-RA database. Ann Rheum Dis 2009;68:1666-72.

40. Margaretten M, Barton J, Julian L, Katz P, Trupin L, Tonner C, et al. Socioeconomic determinants of disability and depression in patients with rheumatoid arthritis. Arthritis Care Res (Hoboken);63:240-6.

41. Hernandez-Garcia C, Vargas E, Abasolo L, Lajas C, Bellajdell B, Morado IC, et al. Lag time between onset of symptoms and access to rheumatology care and DMARD therapy in a cohort of patients with rheumatoid arthritis. J Rheumatol 2000;27:2323-8.

42. Jacobi CE, Mol GD, Boshuizen HC, Rupp I, Dinant HJ, Van Den Bos GA. Impact of socioeconomic status on the course of rheumatoid arthritis and on related use of health care services. Arthritis Rheum 2003;49:567-73.

43. Zyrianova Y, Kelly BD, Sheehan J, McCarthy C, Dinan TG. The psychological impact of arthritis: the effects of illness perception and coping. Ir J Med Sci 2011;180:203-10.

44. Deighton CM, Surtees D, Walker DJ. Influence of the severity of rheumatoid arthritis on sex differences in health assessment questionnaire scores. Ann Rheum Dis 1992;51:473-5.

45. Hallert E, Thyberg I, Hass U, Skargren E, Skogh T. Comparison between women and men with recent onset rheumatoid arthritis of disease activity and functional ability over two years (the TIRA project). Ann Rheum Dis 2003;62:667-70.

46. Ahlmen M, Svensson B, Albertsson K, Forslind K, Hafstrom I. Influence of gender on assessments of disease activity and function in early rheumatoid arthritis in relation to radiographic joint damage. Ann Rheum Dis 2010;69:230-3.

47. Garcia-Gonzalez A, Richardson M, Garcia Popa-Lisseanu M, Cox V, Kallen MA, Janssen N, et al. Treatment adherence in patients with rheumatoid arthritis and systemic lupus erythematosus. Clin Rheumatol 2008;27:883-9.

48. Graell E, Vazquez I, Larrosa M, Rodriguez-Cros JR, Hernandez MV, Gratacos J, et al. Disability measured by the modified health assessment questionnaire in early rheumatoid arthritis: prognostic factors after two years of follow-up. Clin Exp Rheumatol 2009;27:284-91.

49. Kroenke K, Bair MJ, Damush TM, Wu J, Hoke S, Sutherland J, et al. Optimized antidepressant therapy and pain self-management in primary care patients with depression and musculoskeletal pain: a randomized controlled trial. Jama 2009;301:2099-110.

50. Kekow J, Moots R, Khandker R, Melin J, Freundlich B, Singh A. Improvements in patient-reported outcomes, symptoms of depression and anxiety, and their association with clinical remission among patients with moderate-to-severe active early rheumatoid arthritis. Rheumatology (Oxford) 2011;50:401-9. 
Table 1: Changes in disease activity, functional disability and health related quality of life of 134 patients over 12 months

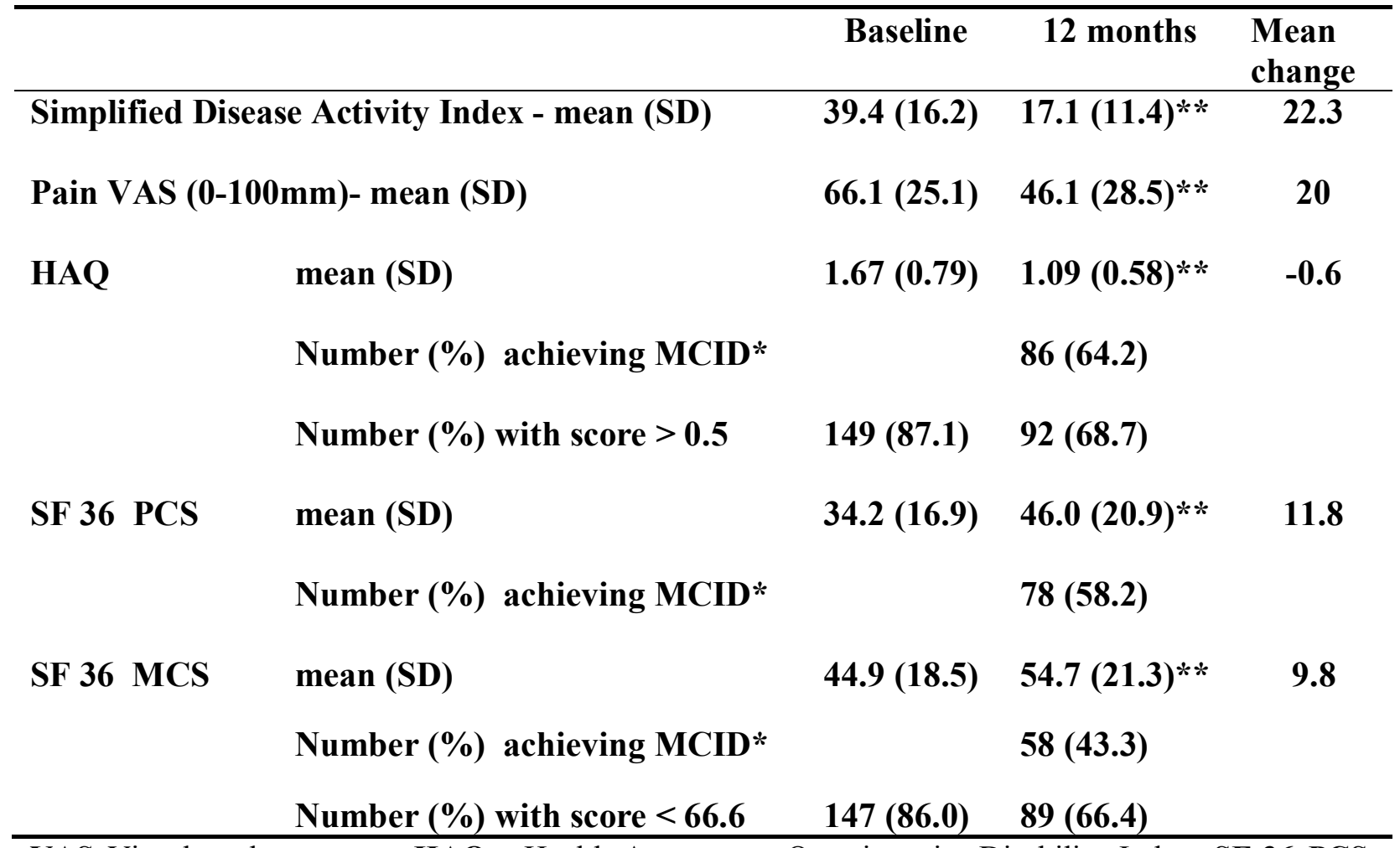

VAS Visual analogue score HAQ - Health Assessment Questionnaire Disability Index, SF-36 PCS Short Form 36 physical component score, SF-36 MCS - Short Form 36 mental component score

*MCID - Minimum clinically important difference defined as changes $\geq \mathbf{- 0 . 2 5}$ for HAQ scores and $\geq 5$ for SF 36 composite scores

** p-value $<0.001$ 
Table 2: Correlations coefficients of functional disability and SF-36 domains and composite scores with disease activity measures at 12 months

\begin{tabular}{|c|c|c|c|c|c|c|}
\hline & & PAIN & PGA & MDGA & SDAI & HAQ \\
\hline \multirow[t]{5}{*}{ HAQ } & & $0.32 * * *$ & $0.35 * * *$ & $0.21 *$ & $0.48 * * *$ & \\
\hline & $\begin{array}{l}\text { Physical } \\
\text { Function }\end{array}$ & -0.11 & -0.11 & 0.05 & $-0.23 * *$ & $-0.44 * * *$ \\
\hline & $\begin{array}{l}\text { Role- } \\
\text { Physical }\end{array}$ & $-0.34 * * *$ & $-0.40 * * *$ & $-0.30 * *$ & $-0.38 * * *$ & $-0.58 * * *$ \\
\hline & Bodily Pain & $-0.51 * * *$ & $-0.55 * * *$ & $-0.37 * * *$ & $-0.52 * * *$ & $-0.63 * * *$ \\
\hline & $\begin{array}{l}\text { General } \\
\text { Health }\end{array}$ & $-0.32 * * *$ & $-0.42 * * *$ & $-0.23 *$ & $-0.41 * * *$ & $-0.58 * * *$ \\
\hline \multirow[t]{4}{*}{$\begin{array}{c}\text { SF-36 } \\
\text { domains }\end{array}$} & $\begin{array}{l}\text { Mental } \\
\text { Health }\end{array}$ & -0.13 & -0.12 & -0.09 & -0.11 & $-0.32 * * *$ \\
\hline & $\begin{array}{c}\text { Role } \\
\text { Emotional }\end{array}$ & $-0.25 * *$ & $-0.32 * *$ & $-0.21 *$ & $-0.26 * *$ & $-0.55 * * *$ \\
\hline & Vitality & $-0.30 * *$ & $-0.34 * * *$ & -0.15 & $-0.35 * *$ & $-0.55 * * *$ \\
\hline & $\begin{array}{c}\text { Social } \\
\text { Functioing }\end{array}$ & $-0.27 * *$ & $-0.32 * *$ & $-0.21 *$ & $-0.25 * *$ & $-0.60 * * *$ \\
\hline \multirow{2}{*}{$\begin{array}{c}\text { SF-36 } \\
\text { composite } \\
\text { scores }\end{array}$} & PCS & $-0.40 * * *$ & $-0.46 * * *$ & $-0.29 * *$ & $-0.46 * * *$ & $-0.71 * * *$ \\
\hline & MCS & $-0.32 * * *$ & $0.439 * * *$ & $-0.24 *$ & $-0.35 * *$ & $-0.67 * * *$ \\
\hline
\end{tabular}

$* \mathbf{p}<0.05 ; * * \mathbf{p}<0.005 ; * * \mathbf{p}<0.001$

PGA patient global assesment, MDGA - physician global assessment, SDAI- Simplified Disease Activity Score, HAQ Health Assessment Questionnaire Disability Index, SF-36 - Short Form 36, PCS - physical component score, MCS mental component score 
Table 3: Predictors of 12-month functional disability by univariate and multivariate analysis

\begin{tabular}{|c|c|c|c|c|c|}
\hline \multirow[b]{2}{*}{ Demographic and clinical features } & \multicolumn{3}{|c|}{ Univariate analysis } & \multicolumn{2}{|c|}{ Multivariate analysis } \\
\hline & $\begin{array}{c}\text { Minimal } \\
\text { Functional } \\
\text { Disability } \\
\text { (HAQ } \leq \mathbf{0 . 5}) \\
\text { n= } 42\end{array}$ & $\begin{array}{c}\text { Substantial } \\
\text { Functional } \\
\text { Disability } \\
\text { (HAQ >0.5) } \\
\text { n=92 }\end{array}$ & p value & OR (95\% CI) & p value \\
\hline Black ethnicity (\%) & $39(92.9)$ & $81(88.0)$ & ns & & \\
\hline Female (\%) & $30(71.4)$ & $79(85.7)$ & 0.05 & $2.6(1.0-6.9)$ & 0.05 \\
\hline Age- mean (yrs) (SD) & $46.3(12.6)$ & 47.9(12.7) & ns & & \\
\hline Symptom duration-mean (months) (SD) & $11.6(7.1)$ & $10.9(6.8)$ & ns & & \\
\hline Poor adherence to treatment (\%) & $6(14.3)$ & $26(28.3)$ & 0.08 & $1.6(0.5-4.9)$ & ns \\
\hline Unemployed & $20(47.6)$ & $58(63.0)$ & 0.13 & $1.1(0.4-2.8)$ & ns \\
\hline Schooling completed- mean (yrs) (SD) & $9.8(2.9)$ & $8.4(3.4)$ & 0.06 & $0.9(0.8-1.1)$ & ns \\
\hline \multicolumn{6}{|l|}{ Baseline visit } \\
\hline Tender Joint Count- mean (SD) & $13.8(8.7)$ & $14.1(7.4)$ & ns & & \\
\hline Swollen Joint Count- mean (SD) & $10.7(7.6)$ & $9.8(5.9)$ & ns & & \\
\hline Pain VAS (0-100mm) -mean (SD) & $53.1(24.7)$ & $67.4(23.1)$ & 0.001 & $1.0(0.9-1.03)$ & ns \\
\hline Patient global assessment VAS (0-100mm)-mean (SD) & $67.9(26.2)$ & $71.6(23.6)$ & ns & & \\
\hline MD global assessment VAS (0-100mm)-mean (SD) & $54.2(23.4)$ & $60.1(19.6)$ & 0.13 & $1.0(1.0-1.1)$ & ns \\
\hline ESR (mm/hour)- mean (SD) & $43.6(35.3)$ & $47.8(26.0)$ & ns & & \\
\hline SDAI- mean (SD) & $39.6(19.2)$ & $40.3(15.1)$ & ns & & \\
\hline HAQ - mean (SD) & $1.2(0.8)$ & $1.9(0.7)$ & $<0.001$ & $2.9(1.3-6.2)$ & 0.01 \\
\hline SF-36 MCS & $50.5(19.5)$ & $43.0(18.8)$ & 0.04 & $1.0(0.97-1.1)$ & ns \\
\hline \multicolumn{6}{|l|}{12 month visit } \\
\hline Pain VAS (0-100mm) -mean (SD) & $41.4(37.0)$ & $63.8(31.1)$ & $<\mathbf{0 . 0 0 1}$ & & \\
\hline SDAI- mean (SD) & $11.1(8.9)$ & $19.8(11.5)$ & $<0.001$ & & \\
\hline Change in pain - mean (SD) & $28.5(19.1)$ & $20.5(17.7)$ & 0.02 & & \\
\hline Change in SDAI - mean (SD) & $25.7(28.7)$ & $11.7(30.9)$ & 0.01 & & \\
\hline
\end{tabular}

VAS visual analogue scale; MD global assessment: Physician global assessment; ESR: Erythrocyte Sedimentation Rate; SDAI: Simplified Disease Activity Index; HAQ: Health Assessment Questionnaire Disability Index; SF-36 MCS - Short Form 36 mental component 
Table 4: Predictors of 12- month SF-36 mental component score by univariate and multivariate analysis

\begin{tabular}{|c|c|c|c|c|c|}
\hline \multirow[b]{2}{*}{ Demographic and baseline features } & \multicolumn{3}{|c|}{ Univariate analysis } & \multicolumn{2}{|c|}{ Multivariate analysis } \\
\hline & $\begin{array}{c}\text { Good Mental } \\
\text { Health } \\
\text { (SF } 36 \text { MCS } \geq 66.6 \text { ) } \\
\text { n= 45 }\end{array}$ & $\begin{array}{c}\text { Suboptimal } \\
\text { Mental Health } \\
\text { (SF } 36 \text { MCS }<66.6 \text { ) } \\
\text { n= 89 }\end{array}$ & $\begin{array}{l}\text { p } \\
\text { value }\end{array}$ & OR (95\% CI) & p value \\
\hline Black ethnicity (\%) & 39 (867) & $81(91.0)$ & ns & & \\
\hline Female (\%) & $33(75.6)$ & $76(84.3)$ & 0.10 & $2.0(0.6-6.4)$ & ns \\
\hline Age- mean (yrs) (SD) & $47.3(12.8)$ & $47.5(12.6)$ & ns & & \\
\hline Symptom duration- mean (months) (SD) & $12.0(7.3)$ & $10.7(6.6)$ & ns & & \\
\hline Poor adherence to treatment $(\%)$ & 7 (15.6) & $25(28.1)$ & 0.13 & $1.1(0.3-3.4)$ & ns \\
\hline Unemployed & $21(46.7)$ & $57(64.0)$ & 0.04 & $3.1(1.1-8.4)$ & 0.03 \\
\hline Schooling completed- mean (yrs) (SD) & $9.7(2.9)$ & $8.5(3.4)$ & 0.04 & $0.8(0.48-1.03)$ & 0.08 \\
\hline \multicolumn{6}{|l|}{ Baseline visit } \\
\hline Pain VAS (0-100mm) -mean (SD) & $52.9(25.0)$ & $68.0(22.6)$ & 0.001 & $1.0(1.0-1.1)$ & 0.02 \\
\hline $\begin{array}{l}\text { Patient global assessment VAS }(0-100 \mathrm{~mm})- \\
\text { mean (SD) }\end{array}$ & $64.6(26.3)$ & $73.4(23.2)$ & 0.05 & $1.0(0.98-1.04)$ & 0.08 \\
\hline $\begin{array}{l}\text { MD global assessment VAS }(0-100 \mathrm{~mm})- \\
\text { mean (SD) }\end{array}$ & $55.6(23.8)$ & $59.6(19.4)$ & ns & & \\
\hline SDAI- mean (SD) & $41.5(19.3)$ & $39.4(14.8)$ & ns & & \\
\hline HAQ- mean (SD) & $1.2(0.9)$ & $1.9(0.7)$ & $<0.001$ & $1.0(1.0-4.4)$ & 0.04 \\
\hline SF-36 PCS & $43.1(20.6)$ & $31.7(14.4)$ & $<0.001$ & $1.0(0.9-1.1)$ & ns \\
\hline \multicolumn{6}{|l|}{12 month visit } \\
\hline Pain VAS (0-100mm) -mean (SD) & $47.6(37.5)$ & $61.4(32.2)$ & 0.03 & & \\
\hline SDAI- mean (SD) & $12.5(8.9)$ & $19.4(11.9)$ & $<0.001$ & & \\
\hline HAQ- mean (SD) & $0.5(0.5)$ & $1.4(0.7)$ & $<0.001$ & & \\
\hline Change in pain - mean (SD) & $21.2(30.0)$ & $9.5(31.1)$ & 0.04 & & \\
\hline Change in SDAI - mean (SD) & $29.0(20.2)$ & $19.9(16.8)$ & 0.007 & & \\
\hline Change in HAQ - mean (SD) & $0.8(1.0)$ & $0.5(0.8)$ & 0.049 & & \\
\hline
\end{tabular}

VAS visual analogue scale; MD global assessment: Physician global assessment; ESR: Erythrocyte Sedimentation Rate; SDAI: Simplified Disease Activity Index; HAQ: Health Assessment Questionnaire Disability Index; SF-36 PCS - Short Form 36 physical component score 